\section{Biological Action Of Direct Current}

\author{
Muhiddin Halimovich Jalilov, \\ Samarkand Medical Institute, Assistant, Ph.D., Uzbekistan \\ Khudaikulova Shoira Narzullaevna, \\ Samarkand Medical Institute, Senior Lecturer, Uzbekistan
}

\author{
Akhrorov Maruf Nasimovich \\ Samarkand Medical Institute, Assistant, Uzbekistan
}

\author{
G OPEN ACCESS \\ The American Journal of \\ Medical Sciences And \\ Pharmaceutical \\ Research \\ JULY 2020 \\ Page No.: 48-51 \\ Volume-II Issue-VII \\ PUBLISHED: 30 JULY 2020 \\ www.usajournalshub.com/inde \\ x.php/TAJMSPR \\ Copyright: Original content \\ from this work may be used \\ under the terms of the \\ Creative Commons Attribution \\ 4.0 licence.
}

\begin{abstract}
This work is devoted to the study of the effect of direct current on biological tissues, cells and on the weight of the human body. The dielectric constant of certain substances and the resistivity of organs is given. The course of physical and chemical changes under the influence of direct current in cells, tissues and the entire body is indicated.
\end{abstract}

Keywords:Biological tissue, electric field, electrical conductivity, resistivity, direct current, skin resistance, permittivity, galvanization, cell, tissue, blood circulation, current density, charge, ion.

\title{
Introduction
}

All substances are made up of molecules and atoms. Each of them is a system of charges. Therefore, the state of bodies essentially depends on the currents flowing through them and on the acting electromagnetic field. The electrical properties of biological bodies are more complex. The human body is largely composed of biological fluids containing a large number of ions that are involved in various metabolic processes.

Biological tissues conduct electric current in different ways. The main mechanism that characterizes the flow of electric current in living organisms is electrical conductivity due to ionic conductivity. The electrical conductivity of individual parts of the body depends significantly on the resistance of the skin and subcutaneous layers. Skin resistance is determined by the physiological state, age, thickness, places where the temperature and 
humidity of the skin are measured. The current spreads into the body mainly through the blood and lymphatic vessels, mycuses and nerve fibers.

The electrical parameters of biological tissues are characterized by dielectric constant and electrical conductivity [1]. The value of the dielectric conductivity of some dielectrics are given in table 1.

Table 1. Dielectric constant

\begin{tabular}{|l|l|l|}
\hline № & Dielectric constant at $200^{\circ} \mathrm{C}$ & 6,12 \\
\hline 1 & Sodium chloride crystal & 22 \\
\hline 2 & Turpentine & 35 \\
\hline 3 & Nitrobenzol & 26,3 \\
\hline 4 & Ethyl alcohol & 81 \\
\hline 5 & Water & 72 \\
\hline 6 & Egg white & 85 \\
\hline 7 & Blood & 1,00058 \\
\hline 8 & Air & \\
\hline
\end{tabular}

Different issues in the body have unequal electrical conductivity (Table 2).

Table 2. Resistivity of some biological systems

\begin{tabular}{|l|l|l|}
\hline$№$ & Cloths & Resistivity $(\mathrm{om} * \mathrm{~m})$ \\
\hline 1 & Cerebrospinal fluid & $5,5^{*} 10^{-1}$ \\
\hline 2 & Blood serum & $7,1 * 10^{-1}$ \\
\hline 3 & Muscle tissue & 2 \\
\hline 4 & Liver & 10 \\
\hline 5 & Nervous tissue & 25 \\
\hline 6 & Adipose tissue & 50 \\
\hline 7 & Dry skin & $10^{5}$ \\
\hline 8 & Bone without periosteum & $10^{7}$ \\
\hline 9 & Cytoplasms & $0,1-300$ \\
\hline
\end{tabular}

Under the influence of an electric field, ions and complex molecules, colloidal molecules that have adsorbed ions move inside tissues; the movement of water particles also takes place. The speed of movement of different particles is not the same; it depends both on the magnitude of the charge and mass of the moving particles, and on the viscosity of the medium, the field voltage, and other factors. The lower the charge of the ion, the greater the possibility of its penetration into the cell. Thus, monovalent $\mathrm{Na}+$ and $\mathrm{K}+$ cations penetrate into the cell more easily than divalent $\mathrm{Ca}++$ and $\mathrm{Mg}++$, and the latter more easily than trivalent ones. Monovalent anions, such as $\mathrm{Cl}$ - and J-, penetrate the cell more easily than divalent anions such as SO4--.

The rate of passage through the cell membrane, as well as the rate of its diffusion, is determined by the size of the hydrated ion: the lower the degree of hydration of the ion, the smaller its diameter, the greater its rate of passage into the cell. The degree of hydration is not the same for different ions. Potassium attracts less water than lithium; its effective diameter is the smallest, and therefore the speed of its passage into the cage is the greatest. 
According to the ionic theory of excitation, the accumulation of $\mathrm{Na}$ and $\mathrm{K}$ ions at the cathode leads to an increase in the excitability of the cell, since these ions loosen its membrane and increase its permeability. The slower, compared with $\mathrm{Na}$ and $\mathrm{K}$ ions, the movement of $\mathrm{Ca}$ and $\mathrm{Mg}$ ions creates their relative predominance at the anode, which entails a decrease in the excitability of the cell at the anode due to their compaction of its shell [2]. Hydrogen ions accumulate under the cathode, and hydroxyl ions - under the anode. Hydrogen and hydroxyl ions facilitate the movement of an ion from the external environment into the cell and exchange it with ions inside the cell. The penetration of electrolytes into the cell depends on the number of undissociated molecules. A change in $\mathrm{pH}$, at which the number of undissociated molecules increases, increases cell permeability. A change in the ionic conjuncture of the upper layers of the skin leads primarily to irritation of the receptors embedded in the skin, accompanied by a felt tingling sensation or a slight burning sensation; this irritation rapidly reaches the gallop cortex along the corresponding nerve pathways. Irritation of the skin with current causes a well-defined local hyperemia under the electrodes, which lasts up to 2 hours after galvanization. Such prolonged hyperemia is itself a curative factor. It also arises in connection with the formed histamine and is accompanied by an increase in metabolic processes, the formation of biologically active substances and thus serves as a source of prolonged neuroreflex irritations. Hyperemia enhances regeneration processes and resorption of tissue decay products. Opening of the reserve capillaries of hyperemic skin leads to an increase in the diffuse surface of tissues and an increase in the permeability of the walls of blood vessels; the latter promotes the absorption of medicinal substances introduced into the skin using a constant current. Changes in ionic equilibrium under the influence of direct current are not limited to the skin, but propagate along the course of the current lines of force, which mainly pass on the part of the body located between the electrodes. In this case, electrolyte ions of different signs and ionized molecules, moving, accumulate at semipermeable membranes and form polarization zones in cells and tissues. A socalled polarization current arises in them, the electromotive force of which has a direction opposite to the acting current; this leads to an increase in tissue resistance.

Complex physicochemical changes occurring in the skin and other tissues cause the body's responses, which are based on the neuroreflex mechanism. Depending on various conditions, these reactions can be more or less limited or general.

To obtain the best therapeutic success, it is necessary to apply irritation mainly to the skin of those metameres where the painful process is localized. Under the influence of these skin irritations, in the depths of all tissues that make up this metamer, reactions occur, apparently associated with an improvement in blood circulation, changes in cellular metabolism, etc., which ultimately may entail the restoration of normal relationships in tissues of the painful focus and contribute to the patient's recovery or improve his condition. When the current passes through the nerve, the excitability of the latter changes; this change in the excitability of the nerve is called the whisker electric current. At the cathode there is an increased excitability to stimuli, at the anode - decreased. A decrease in excitability under the anode when exposed to a direct current of low intensity is used in medical practice to reduce pain. With a decrease in the functional capacity of the tissue, cathode galvanization often leads to an increase in excitability.

As a result of physicochemical changes under the influence of direct current in cells 


\section{ISSN (e): 2689-1026}

DOI: https://doi.org/10.37547/TAJMSPR/Volume02Issue07-08

and tissues, significant functional shifts occur on the part of the peripheral and central nervous system, and thereby on the part of organs and tissues of the whole organism. The nature of these reactions can be different; it depends on the intensity, duration and localization of exposure, the polarity of the electrodes and the state of the body. By closing and opening a direct current, it is possible to cause muscle contraction when irritating both the motor nerve and the muscles themselves.

Pulsed direct current is widely used for diagnostic and therapeutic purposes.

Direct current also causes morphological changes in tissues. Studies of the skin exposed to this current have shown changes in their intensity and nature, both in the epidermis and in their own skin, depending on the density and polarity of the current. The epidermis thickened, its cells swelled, the number of cells increased, the connective tissue became edematous; later, the stage of enhanced mitosis began in the epithelium, and then in the connective tissue. The action of direct current is not limited only to the place of its application, but also extends to distant organs and tissues, primarily innervated by the corresponding segment of the spinal cord. After a short-term spasm of blood capillaries, their expansion occurs, and an increase in the permeability of the walls, improves blood and lymph circulation, and the process of resorption is enhanced.

With general galvanization in the blood, the content of leukocytes increases, the ROE is somewhat accelerated. Changes in blood circulation are reflected in the course of trophic processes, which helps to restore the conduction of nerve pathways and enhance the regenerative processes of nerve elements. The metabolism rises.

When the nerve elements of the sensory organs are irritated by direct current, reactions that are adequate to them can be obtained. Thus, the effect on the auditory nerve causes a sensation of noise or ringing in the ears. When the current is closed and opened, the sensation of a flash of light, called phosphene, appears in the eye area, etc.

With general galvanization, when the whole body is exposed, the number of heartbeats decreases.

Direct current affects the evacuation and secretory functions of the gastrointestinal tract, as well as the functional state of other organs, including endocrine.

\section{References}

1. Moodle.sammi.uz. Module 2. Lessons 2. Topic 20 "The effect of the electromagnetic field on biological objects".

2. Khudoikulova Sh.N., Abduvohidov A.A. "Biological action of direct current". Biology wa tibbiyot muammolari. 74 international scientific and practical online conference.

Samarkand 2020y. 